\title{
Estimating dietary requirements for vitamin D: a systematic review of intake-status relationship to inform European recommendations
}

\author{
K. M. Seamans ${ }^{1}$, A. P. Fitzgerald ${ }^{2,3}$, M. Kiely ${ }^{1}$ and K. D. Cashman ${ }^{1,4}$ \\ ${ }^{1}$ Vitamin D Research Group, School of Food and Nutritional Sciences, ${ }^{2}$ Department of Epidemiology and Public Health, \\ ${ }^{3}$ Department of Statistics, and ${ }^{4}$ Department of Medicine, University College Cork, Ireland
}

The Institute of Medicine Dietary Reference Intake (DRI) committee in North America recently established an Estimated Average Requirement and RDA value for vitamin D based on target serum 25-hydroxyvitamin D (s25(OH)D) concentrations of 40 and $50 \mathrm{nmol} / \mathrm{l}$, respectively, which support bone health outcomes ${ }^{(1)}$. The committee used data from nine randomised controlled trials $(\mathrm{RCT})$ with vitamin $\mathrm{D}_{3}$ performed in Europe $\left(>49.5^{\circ} \mathrm{N}\right)$ and Antarctica $\left(78^{\circ} \mathrm{S}\right)$, during their respective winter seasons (with minimal UV blue sun exposure), to establish regression equations of the simulated response of s25(OH)D concentration to total vitamin $\mathrm{D}$ intake, and used these to establish the DRI values for the target $\mathrm{s} 25(\mathrm{OH}) \mathrm{D}$ concentrations ${ }^{(1)}$. However, the DRI committee also highlighted that the regression analysis had several assumptions/uncertainties that may have had implications for its DRI estimates ${ }^{(1)}$. The present work used a systematic review approach to identify relevant RCT with vitamin $\mathrm{D}_{3}$, followed by meta-regression to explore the vitamin $\mathrm{D}$ intake-status relationship, and in particular, the appropriateness of the regression analysis approach used by the DRI committee for making European vitamin D recommendations.

Methods included a structured search on Ovid MEDLINE; rigorous inclusion/exclusion criteria, data extraction and meta-regression (using different model constructs). In particular, priority was given to data from winter-based RCT $>49.5^{\circ} \mathrm{N}$ and $78^{\circ} \mathrm{S}$ for the metaregression ( $n 12$ out of total $44 \mathrm{RCT}$ identified in our search).

A weighted linear-model meta-regression analyses of natural $\log (\ln )$ total vitamin D intake (i.e. diet and supplemental vitamin D) $v$. s25(OH)D achieved in winter (the model used by the DRI committee ${ }^{(1)}$ ) produced a curvilinear relationship and predicted an achieved mean $[95 \%$ lower $\mathrm{CI}] \mathrm{s} 25(\mathrm{OH}) \mathrm{D}(\mathrm{nmol} / \mathrm{l})=9.2[8.5] \mathrm{ln} *($ total vitamin $\mathrm{D}$ intake). Use of non-transformed total vitamin $\mathrm{D}$ intake data provided a more linear relationship with a predictive equation of achieved mean $[95 \%$ lower $\mathrm{CI}] \mathrm{s} 25(\mathrm{OH}) \mathrm{D}(\mathrm{nmol} / \mathrm{l})=0.021$ [0.011]*(total vitamin D intake) +43.569 [36.137].

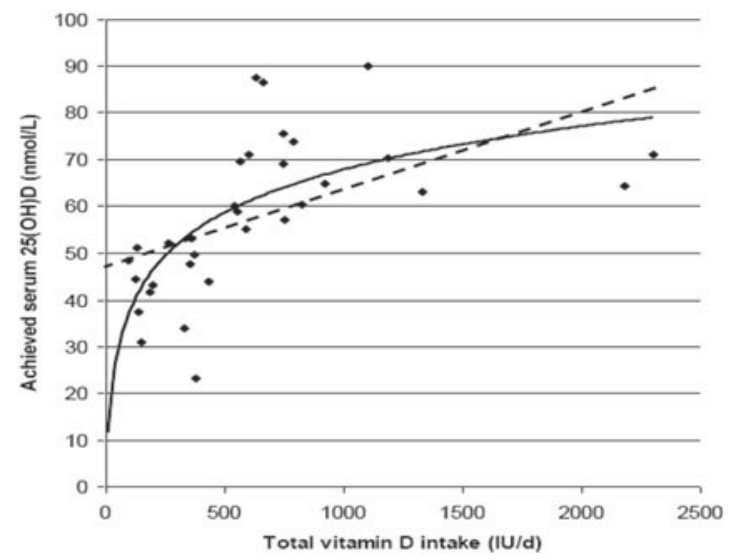

In conclusion, while the relation of $\mathrm{s} 25(\mathrm{OH}) \mathrm{D}$ to vitamin $\mathrm{D}$ intake is critical to the establishment of dietary requirements, the model used to describe this relationship needs to be considered carefully especially if s25(OH)D less than $50 \mathrm{nmol} / \mathrm{l}$ are chosen as the threshold.

This work was supported by European Framework VI: EURopean micronutrient RECommendations Aligned (EURRECA) $2007-2011$.

1. Institute of Medicine Food and Nutrition Board (2010). Dietary Reference Intakes for Calcium and Vitamin D. Washington, DC: National Academies Press. 